\title{
MARCA TURÍSTICA Y MOVIE MAPS. IDENTIDAD, CINE Y PUBLICIDAD COMO PRODUCTO DE CONSUMO.
}

\section{Touristic brand and movie maps. Identity, movies and publicity as consumption product.}

\author{
Pedro A. Hellín Ortuño ${ }^{1}$ \\ Salvador Martínez Puche ${ }^{2}$
}

\section{Resumo}

A publicidade turística busca gerar um sentimento de atração, cuja projeção central não deixa de ser uma mistura de ficção e realidade com o objetivo de diferenciar o destino turístico. Dado que o turismo é essencialmente uma experiência visual, nos últimos anos tem revitalizado a sua relação com a produção fílmica para gerar novos produtos turísticos. As localizações cinematográficas estão propiciando atrativos percursos através de lugares convertidos em espaços "semantizados" pela ficção fílmica, cujos itens mais notáveis são colocados sobre os planos e mapas que servem como instrumento de promoção, indução e orientação turística, além de auxiliar na construção da marca e conferir identidade diferenciada aos destinos.

Palavras-chave: Marca turismo, cinema, filme mapas, publicidade.

\begin{abstract}
Tourism advertising find to generate a sense of attraction, whose projection it is a mixture of fiction and reality for the differentiation of the tourist destination. As tourism is essentially a visual experience, in recent years has revitalized its relationship with the film to generate new products of tourism consumption. The film locations are attractive walks through propitiating places become spaces "semantizados" for fiction film, whose most notable items are placed on plans and maps that serve as promotional tools, induction and orientation in the tourism and help the branding, as they provide a distinct identity for the destination.
\end{abstract}

\footnotetext{
${ }^{1}$ Profesor Contratado Doctor. Imparte las asignaturas de Diseño de la Imagen Corporativa, y Sistemas y Procesos de la Publicidad y las Relaciones Públicas. Universidad de Murcia. Facultad de Comunicación y Documentación. Campus Universitario de Espinardo, s/n. 30100 Murcia. +34 868888 411. E-mail: phellin@um.es

${ }^{2}$ Doctorando en la universidad de Murcia -España e Profesor Colaborador en las asignaturas de Comunicación Audiovisual y Psicología de la Comunicación de la Licenciatura de Publicidad y Relaciones Públicas. Universidad San Jorge. Facultad de Comunicación. Autovía A-23 Zaragoza-Huesca, km. 510. 50830 Villanueva de Gállego (Zaragoza). Tel.: +34 976060 100. E-mail: smartinez@usj.es
} 
Marca turística y movie maps. Identidad, cine y publicidad como producto de consumo de Pedro A. Hellín Ortuño e Salvador Martínez Puche

Keywords: tourism mark, cinema, movie maps, advertising.

\section{Resumen}

La publicidad turística busca generar un sentimiento de atracción, cuya proyección no deja de ser una mezcla de ficción y hechos reales en busca de la diferenciación del destino turístico. Como el turismo es esencialmente una experiencia visual, en los últimos años se ha revitalizado su vinculación con el cine para generar nuevos productos de consumo turístico. Las localizaciones cinematográficas están propiciando atractivos recorridos a través de lugares convertidos en espacios "semantizados" por la ficción fílmica, cuyos ítems más destacados se ubican sobre planos y mapas que actúan como instrumentos de promoción, inducción y orientación en la visita turística y ayudan a la creación de marca, ya que aportan una identidad diferenciada al destino.

Palabras-clave: Marca turística, cine, movie maps, publicidad.

¿Qué es viajar? ¿Cambiar de lugar? No. Cambiar de ilusiones y de prejuicios. JACQUES ANATOLE FRANCE

\section{INTRODUCCIÓN}

El turismo es, en nuestra cultura posmoderna, una de las expresiones más características del nuevo consumo, ya que se basa en la fuerte significación atribuida al tiempo de ocio y su separación de la vida cotidiana (Urry, 1990). El tiempo que dedicamos al turismo es el deseado y valorado tiempo vacacional; en el que depositamos enormes expectativas, adquiriendo así las vacaciones un importante significado emocional, de forma que "se exige a los productos turísticos una calidad acorde con esas expectativas, que no sólo han de cumplirse, sino también comunicarse, estableciéndose una lucha comercial entre destinos (sobre todo entre los desarrollados) basada en la comunicación de la calidad de su oferta" (Hellín Ortuño, 2007:209), donde la diferenciación solo se puede conseguir mediante la posesión de una marca desarrollada. La marca, por tanto, se convierte en el vehículo a través del cual se identifica la oferta, se la presenta de forma atractiva y se intenta provocar reacciones de deseo y generar expectativas positivas. La función de la marca turística es lograr el posicionamiento deseado en la mente de los consumidores (la diferenciación) y generar una Imagen Corporativa favorable (el deseo).

Aunque el turismo es un fenómeno de complejas dimensiones, que dificultan su abstracción hasta medidas concretas, resulta un puente de conocimiento con la sociedad, por 
las evidentes relaciones que mantiene con ella. Una de las grandes influencias sociales en el turismo actual es la constante presencia de la comercialización en todos los aspectos de la vida. Esto viene conformado por el cambio de una economía de "servicios" a una economía “de experiencias", donde el nuevo centro de atención será proporcionar experiencias únicas que interesen a cada consumidor, de forma individualizada. Ritzer (1999) y otros autores consideran que la comercialización de la experiencia puede considerarse como característica definitoria de la etapa actual del capitalismo. Es así que la publicidad actúa como agente fundamental y comunicador extraordinario, tanto en lo que se refiere a campañas orientadas a crear la imagen global de una región determinada, asociándola con determinados valores o características particulares, como en la llamada publicidad informativa.

Uniendo la doble perspectiva expuesta: necesidad de crear una marca turística diferenciada y posibilidad de comercializar la experiencia, aparece un nuevo producto turístico, los movie maps, que se apoyan en que el relato fílmico y el viaje turístico se basan, según Michel de Certau (Augé, 2004), en la doble necesidad de "ver” y “hacer”. Es decir, el cine contribuye con su poder simbólico a crear y "soportar"3 la "imagen" de un territorio a través de representaciones cinematográficas (experiencia fílmica), que producen significados. Estos "imaginarios" son mediadores de la realidad y (des)encadenan un proceso de reinterpretación sugerido por la vivencia particular nacida al contemplar la película. Como afirma Gubern, “el observador, durante la acción de mirar, está comparando lo que ve con los modelos perceptivos adquiridos en su anterior experiencia cultural, prestando más atención a lo nuevo y desconocido que a lo obvio y familiar" (Gómez 2002:3). De manera que estos estímulos pueden incitar y condicionar la posterior visita (experiencia turística) a lugares, tal vez, "reconocibles", pero exhibidos y percibidos de un modo más atractivo, diferente e "inédito".

Las actuales sinergias entre cine y turismo, dos industrias del entretenimiento complementarias, se materializan en estrategias y acciones comunicativas muy rentables y eficaces, que se potencian mutuamente aprovechando lo que se conoce como "cross media" o narraciones infinitas, integración de múltiples medios para contar un relato de manera continua. En este sentido, se puede afirmar que "los datos de las experiencias culturales están formados por modelos de vida social novelados, idealizados o exagerados que son de dominio público, a través del cine, la fícción, la retórica (...) y los espectáculos" (MacCannell 2003:33). Más concretamente, "hemos de tener en cuenta que todas las producciones culturales, incluidas las propias del turismo, son signos. Relatos simbólicos

\footnotetext{
${ }^{3}$ Además de ser sinónimo de "mantener y conservar", nótese otra de sus acepciones técnicas: "material en cuya superficie se registra información, como el papel, la cinta de vídeo o el disco compacto". (En Real Academia de la Lengua Española. www.rae.es).
} 
ritualizados basados en modelos que pretenden transportar al individuo más allá de sí mismo y de las restricciones de la experiencia diaria (...), bajo el poder hipnótico del relato o del ámbito temático creado para servir de sostén simbólico" (San Nicolás 2008:125). La tematización turística otorga a los espacios urbanos o rurales un sentido, conforme a los utilitaristas planteamientos de la explotación económico-comercial, que también participa en la definición del territorio como una compleja unidad de significado y una permanente construcción colectiva en la que la comunicación cumple una función básica (Bustamante 2000). Si bien, muchas veces, asistimos a la progresiva sustitución de la realidad históricosocial por su simulacro: "la relación entre lo real y el signo se ha invertido: el simulacro en el mundo posmoderno determina lo real" (Cohen 2005:16).

Así pues, a pesar de que la imagen de París que se muestra en las tradicionales postales y guías turísticas está idealizada, "poco tiene que ver", atendiendo al componente de "visibilidad" del turismo, por ejemplo, con el intrigante y misterioso París del best seller y posterior Blockbuster de El Código Da Vinci (2006) o con el amable y apacible barrio parisino de Montmartre donde transcurre el exitoso filme de Amélie (2001). La puesta en escena del destino turístico, en un ejercicio de superación simbólica, se transforma literalmente en un escenario de ficción en el que revivir la experiencia del relato cinematográfico. La percepción de la ciudad ya no se efectúa a partir de los elementos urbanísticos capturados por el ojo, que está influenciado por los instrumentos convencionales de promoción turística, sino que se inspira en el poder evocador de la memoria que reconstruye el territorio geográfico con sucesivas imágenes y sensaciones anticipadas en la sala de proyección.

El movie tourism, es decir, el turismo inducido por el cine, es un fenómeno cada vez más extendido que viene a redefinir la experiencia del turista convertido ahora en espectador-actor de una ficción limitada en el espacio, pero no en el tiempo. Los movie maps delimitan en un plano el itinerario por las localizaciones de un rodaje que, sin embargo, trasciende el lugar físico, conformando un recuerdo imaginario, para adquirir una dimensión diegético-cognoscitiva del entorno. Pues bien, ambos conceptos se combinan subsidiariamente en las nuevas estrategias de explotación y promoción turística que se enmarcan en el contexto de las industrias del ocio y de la sociedad del espectáculo; la idea es que, además de un producto, sea un atributo de la marca-turística por su elevado potencial simbólico.

\section{EL VIAJE: UNA EXPERIENCIA VISUAL Y MEDIATIZADA}


Marca turística y movie maps. Identidad, cine y publicidad como producto de consumo

El viaje y el cine, de forma real y virtual respectivamente, implican dinamismo y movimiento en un doble sentido: como experiencia individual y como noción simbólica de la modernidad y el progreso histórico. En este sentido, el cinematógrafo puede considerarse en términos funcionales y fundacionales como una derivación del tren. Paul de Kock en 1842 había presagiado ya esta vinculación conceptual afirmando: "El ferrocarril es la verdadera linterna mágica de la naturaleza" al convertir el encuadre vertiginoso de la ventanilla en una animación visual (Virilio 2003:79). La sensación de movimiento es, definitivamente, la esencia compartida por el cine y el turismo. Pero, además de suponer un desplazamiento espacial, lo relevante es que el movimiento también implica transcurso de tiempo consumido.

Por otra parte, como afirma Hernández Ramírez, "la experiencia turística es, en gran medida, visual" (2004:1). Hoy día las motivaciones del sujeto al iniciar un viaje no son la pasión por descubrir territorios ignotos (como el explorador) ni vivir una experiencia "contemplativa" e íntima en lugares ya descubiertos (como el viajero). El interés del turista surge de la voluntad de registrar en imágenes su recorrido y de verificar y revivir a través de ellas otras ya conocidas y preparadas para él por las estrategias publicitarias de la industria turística (Urry, 1990; Del Rey-Reguillo, 2007b). Como sostiene Augé, “el viaje (...) construye una relación ficticia entre mirada y paisaje (...) donde el individuo se siente como [un] espectador" y esta posición es la que constituye "lo esencial del espectáculo" (2004:91).

"Como turistas somos cazadores de símbolos, y cuando viajamos lo hacemos en busca de experiencias, aunque éstas - y el turista normalmente es consciente de ello- son simuladas especialmente para nuestro disfrute" (Hellín Ortuño, 2007:211). La mirada del turista, por tanto, se construye a partir de la acumulación de signos en busca de señales de las demostraciones de tipicidad y de autenticidad. Por eso es preciso para la determinación de la personalidad de un destino diferenciarla de los demás, seleccionar o ponderar alguno de sus atractivos como el más representativo.

De ahí el interés por identificar, capturar y hacer suyo (mediante la fotografía, la grabación de la cámara de vídeo o del teléfono móvil), lo que ha aparecido ante sus ojos como algo destacado y significativo en las guías turísticas que le han persuadido a viajar. Para el turista la experiencia viajera "más que vivida, se demuestra como una sensación [intrínsicamente] relacionada con la mirada (...) que es un referente primordial" (Benet, 1999:37). Por eso el componente icónico-visual (fotográfico y fílmico) sigue ocupando un lugar preferente respecto al texto en los materiales publicitarios de campañas turísticas. Si bien, algún autor defiende las palabras como un constructo evocador previo a la imagen o el 
Marca turística y movie maps. Identidad, cine y publicidad como producto de consumo

mito del no lugar, entendido como el espacio imaginario sugerido en los folletos (Augé, 2004:98).

El cine, como hemos comentado en párrafos anteriores, crea universos simbólicos y de sentido en los que intervienen un conjunto de signos y códigos definidos por los mismos criterios y procedimientos de interpretación, que dan como resultado el reconocimiento más que el conocimiento (Op. Cit.:39). A través de la multitudinaria difusión de sus representaciones reiteradas constantemente, el medio cinematográfico ha configurado la imagen cultural colectiva y ha confirmado la noción vivencial subjetiva que tiene cada individuo acerca de lugares no conocidos in situ. Según Burguess y Gold, la mediatización contribuye de un modo decisivo a la manera en que el individuo concibe la realidad (Gámir y Valdés, 2007), aunque esta visión pueda correr el riesgo de ser reduccionista o estar "manipulada".

El acto perceptivo se convierte en la inferencia de un futuro de experiencias que se edifica sobre un presente que no da nunca garantías para él, como afirma Merleau-Ponty (Gómez Tarín, 2002). Se trata de un acto de fe, de una creencia afectada por el imaginario y el contexto, que se ejercen sobre un mundo cuya realidad resulta intangible y requiere la mediación, en palabras de Neisser, de "un complejo sistema que interpreta y reinterpreta la información sensorial” (Op. Cit:6). Como afirma el director Jacques Tourner, cuando rueda una película "la cámara no lo ve todo, yo sí" (Virilio, 1989:25).

La pantalla difumina los límites entre ficción y realidad, entre realidad y verdad (MacCannell, 2003). La imagen fática, que fuerza la mirada y retiene la atención, sólo se centra en zonas específicas, mientras el contexto desaparece en la indeterminación de una experiencia espacio-temporal desanclada (Virilio, 1989:26). De este modo, el cine puede alterar la realidad percibida y llevar a cabo ya no una representación, sino más bien una recreación de la misma, como señalan Hyounggon y Richardson (Hernández Ramírez, 2004).

Este factor es determinante a la hora de modificar y transformar los rasgos identitarios conforme a fórmulas esteticistas y significantes en un proceso de codificación con fines comerciales en el que "la autenticidad misma procede a habitar la mistificación" (MacCannell, 2003:123). Es el primer paso hacia, lo que Lukács denomina, la homogeneidad y la estandarización cultural del capitalismo de ficción, que convierte las experiencias en productos de consumo masivo a través de la reificación de lo inmaterial (Jameson, 1991).

Por ejemplo, John Wayne es la única referencia del "auténtico" vaquero para los espectadores, aficionados o no, al cine del género Western y en torno a este actor y sus 
películas se genera todo un imaginario sobre una forma de vida, unos paisajes y unas circunstancias inscritas en una etapa histórica de los Estados Unidos. Estos filmes son el referente de conocimiento popular y globalizado en detrimento de los libros de Historia y, además, atraen, inspiran y guían el itinerario ficcional de los turistas en una dimensión plagada de ilusiones postergada ${ }^{4}$. "Los espectadores no fabrican sus imágenes mentales a partir de lo que les es dado de modo inmediato para que vean, sino a partir de recuerdos (...) e imágenes que crean a posteriori" (Virilio, 1989:12) con la participación de elementos vivenciales, culturales y sociales. Como explica De Lauretis, la percepción no consiste en hacer una copia de la realidad sino en simbolizarla, de modo que adquiere un considerable elemento de ficción (Gómez Tarín, 2002).

\section{EL CINE: UN INDUCTOR DE LA VISITA TURÍSTICA}

El cine está ligado a la mirada y el tiempo, categorías inherentes asimismo al concepto de viaje. Éste, a su vez, remite al hecho de disfrutar del tiempo mirando, observando y descubriendo realidades. Por tanto, en una especie de reciprocidad redundante, el proceso cinematográfico permite viajar al "exhibir algo destinado a ser mirado". Así pues, no es de extrañar que la representación turística de un lugar o un monumento reciba el clarificador nombre de "vista" (Del Rey-Reguillo, 2007a).

Los lazos de la unión funcional entre cine y turismo surgen en las primeras proyecciones públicas del cinematógrafo a finales del siglo XIX, cuando las pantallas se convierten en escaparates de exhibición espectacular de la geografía y la cultura planetarias para el hombre moderno. Pero la experiencia de la percepción visual ya no es de la realidad, sino más bien de su reflejo mediado, como apuntamos en párrafos anteriores, debido a la habilidad del cine para colonizar fácilmente la imaginación del espectador a través de sus imágenes y sus relatos (Op. Cit.).

Durante el primer tercio del siglo XX los gobiernos intuyen la capacidad simbólica del revolucionario aparato del cinematógrafo, que es un tomavistas y un proyector al unísono, para ser utilizado como medio masivo de difusión con el propósito de dar a conocer y promocionar lugares, además de atraer turistas (Sandoval Martín, 1998).

Si bien, no ha sido hasta hace sólo una década cuando se han empezado a implementar las bases científicas y epistemológicas para establecer sinergias que favorezcan el desarrollo de estrategias promocionales conjuntas entre la industria turística y la

\footnotetext{
${ }^{4}$ Llama la atención el hecho de que en Tailandia exista interés por convertir la "cultura cowboy" en una atracción turística local. (Cohen 2005:12).
} 
cinematográfica bajo la denominación de "turismo inducido por el cine" (o movie tourism) (Rosado C. y Querol P., 2006:29; Hernández Ramírez, 2004:3). En este sentido, es decisivo el estudio cuantitativo llevado a cabo por Riley, Baker y Van Doren en 1998 porque pone de manifiesto la influencia que había tenido el rodaje de 10 películas comerciales en el incremento de la afluencia de turistas (en torno al 50\%) a sus escenarios o localizaciones durante los 5 años posteriores al estreno (Op. Cit.).

La efectividad del discurso cinematográfico frente, por ejemplo, al de la publicidad gráfico-audiovisual más tradicional se fundamenta en cuatro parámetros:

- La implicación del espectador por medio de una identificación imaginaria, sustentada en el poder de atracción, seducción y fascinación del cine convertido en un signo o símbolo más evocador que denotador; es identificación narrativa, que se produce en el ámbito consciente, es decir, cognitivo: con los personajes y los hechos acaecidos, y es inconsciente, o sea, emotivo: con los conflictos existenciales planteados (González Requena 1999). Se refiere a la relación dramatis personae que se produce entre cada uno de los miembros del público y lo proyectado.

- La suspensión de la incredulidad experimentada al ver una película hace que la historia de ficción sea percibida como si fuera la misma realidad. Es el "efecto de realidad" del que habla González Requena (1999:116) que produce el cine cuando representa al mundo en una pantalla y ejerce de mediador ante la falta de experiencia perceptiva directa del espectador. Así se refuerzan y retienen motivaciones y sentimientos asociados a imágenes e historias.

- La inmersión espectatorial en el relato fílmico facilitada por las condiciones ambientales específicas de percepción del cine que se "manipulan con el fin de neutralizarlas para que el sujeto pueda proyectarse en el interior del universo que el espectáculo le ofrece": gran pantalla, sala oscura, silencio colectivo, sonido y música envolventes y voluntariedad del acto (G. Requena, 1999:104; Del Rey-Reguillo, 2007a). Aunque el consumo cinematográfico en las multisalas ha ido disminuyendo en los últimos años a causa de la proliferación de los equipamientos domésticos digitales (DVD y Dolby Surround), así como de las descargas legales e ilegales de filmes a través de Internet. 
Marca turística y movie maps. Identidad, cine y publicidad como producto de consumo

- El consumo vicario de experiencias se traduce en el deseo o "la sensación alterada, creada, intensificada" ("influencia") de reconocer in situ las imágenes turísticas idealizadas ("modelo") representadas o anticipadas en la pantalla de cine ("medio"). Este esquema de MaCcannell (2003:34 y ss.) sirve para explicar el proceso de producción cultural en el que se inscriben las prácticas del cine y el turismo. La interacción entre ambas industrias ha dado origen a un nuevo tipo de turista denominado "set-jetters" (en inglés set significa "escenario" y jet "volar, viaje en avión"). Según María Eugenia Brito, responsable de la Oficina de VisitBritain ${ }^{5}$ en Madrid, se trata de personas que "van viajando a los sítios que aparecen en las películas porque les han impresionado" (Hosteltur, 2006:10).

\section{MOVIE MAPS: RUTAS POR LUGARES FICCIONALIZADOS}

Las film commissions son las entidades encargadas de aunar y gestionar eficazmente los intereses de la industria audiovisual y la industria turística para conseguir, por una parte, la captación de rodajes y, por otra, el aumento de visitantes tras la difusión multitudinaria del filme. En cualquier caso, pretenden ser una herramienta para la dinamización social, el desarrollo económico y la desestacionalización turística de un determinado espacio geográfico. Se trata, en la mayoría de las ocasiones, de oficinas públicas sin ánimo de lucro promovidas por el gobierno de un país, región o ciudad (Film Office), cuyo objetivo es dar a conocer y promocionar un territorio para incentivar y atraer rodajes audiovisuales, así como establecer posteriores estrategias de marketing turístico. Además de la promoción, otras funciones esenciales son informar, asesorar y colaborar en las diversas fases de la producción, intercediendo ante las diversas administraciones, empresas y particulares. A veces, incluso, actúan como ventanilla única a la hora de tramitar, conceder o denegar permisos o licencias. También forman parte de estas entidades especializadas las Cámaras de Comercio, Asociaciones Empresariales, Patronatos de Turismo, etc. (Rosado y Querol 2006).

Entre sus instrumentos de actuación destacan los movie maps. Son mapas o planos donde se incluye un recorrido por los principales hitos que aparecen en las películas de mayor éxito o impacto y en series de televisión. Algunos movie maps llegan a presentarse en formato SIG (Sistema de Información Geográfico) desplegando escenas de filmes una vez se han seleccionado determinados puntos del mapa o plano y sirven para orientar o dirigir la

\footnotetext{
${ }^{5}$ Organismo público dependiente del Ministerio de Cultura, Medios y Deporte que se encarga de promocionar internacionalmente el Reino Unido como destino turístico.
} 
Marca turística y movie maps. Identidad, cine y publicidad como producto de consumo de Pedro A. Hellín Ortuño e Salvador Martínez Puche

visita turística.

En el caso español destacan dos iniciativas impulsadas, respectivamente, por Barcelona/Catalunya Film Commission y Andalucía Film Commission. En el primer caso, los denominados Movie Walks (paseos de cine) consisten en diversas rutas por la ciudad condal para descubrir los escenarios urbanos de películas como Vicky, Cristina, Barcelona (2008), Todo sobre mi madre (1999), Una casa de locos (2002), El perfume (2006) o Manual d'Amore 2 (2007), entre otras. En el segundo, las rutas turísticas son de dos tipos:

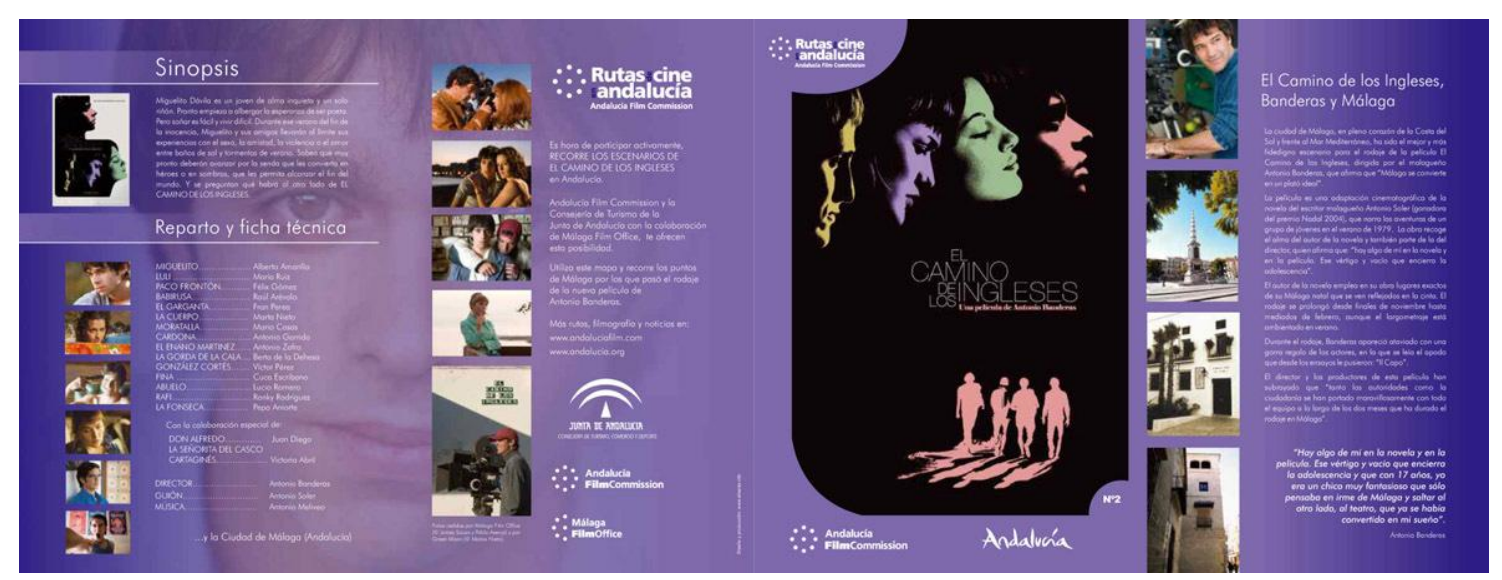

Fig. 1.1

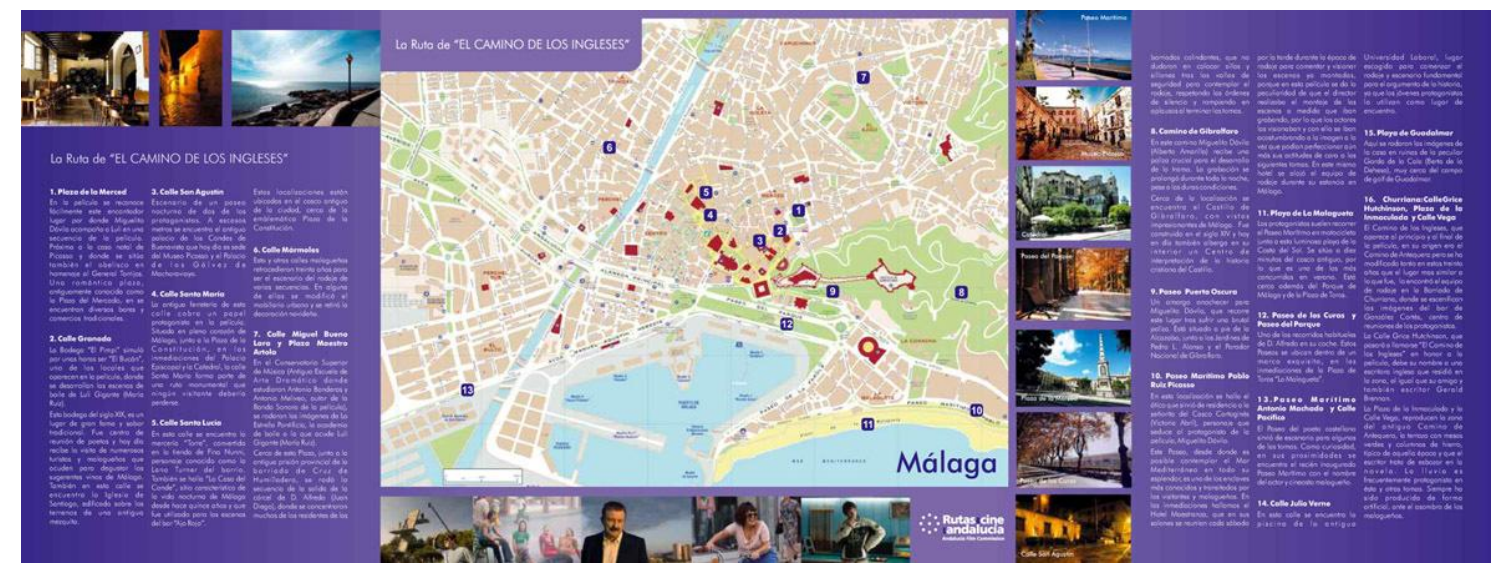

Fig. 1.2

por una parte las que ponen en valor diversas películas rodadas a lo largo del tiempo en territorios andaluces (Almería y el Far West) y, por otra, los recorridos relativos a películas estrenadas recientemente: Carmen (2003), El camino de los ingleses (2006) y el Capitán Alatriste (2006), por ejemplo.

A continuación, se adjuntan algunos ejemplos de movie maps que promocionan diferentes localizaciones cinematográficas como destinos turísticos, ya sea en espacios urbanos o en ámbitos regionales o nacionales, ubicados en España (figuras 1.1, 1.2. y 2.1, 2.2), Gran Bretaña (figuras 3.1, 3.2 y 4.1, 4.2) y Estados Unidos (figuras 5.1 y 5.2). 
Marca turística y movie maps. Identidad, cine y publicidad como producto de consumo de Pedro A. Hellín Ortuño e Salvador Martínez Puche 
Marca turística y movie maps. Identidad, cine y publicidad como producto de consumo de Pedro A. Hellín Ortuño e Salvador Martínez Puche

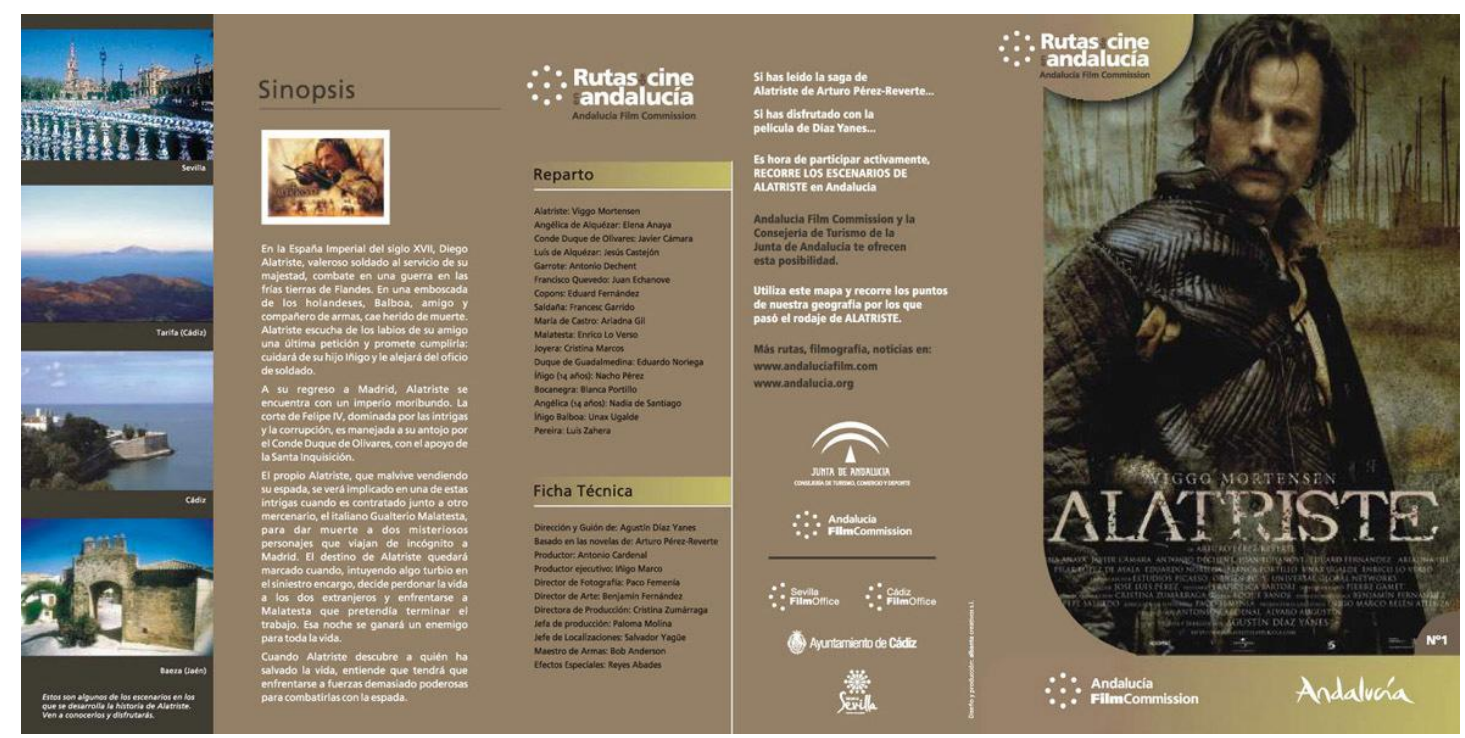

Fig. 2.1
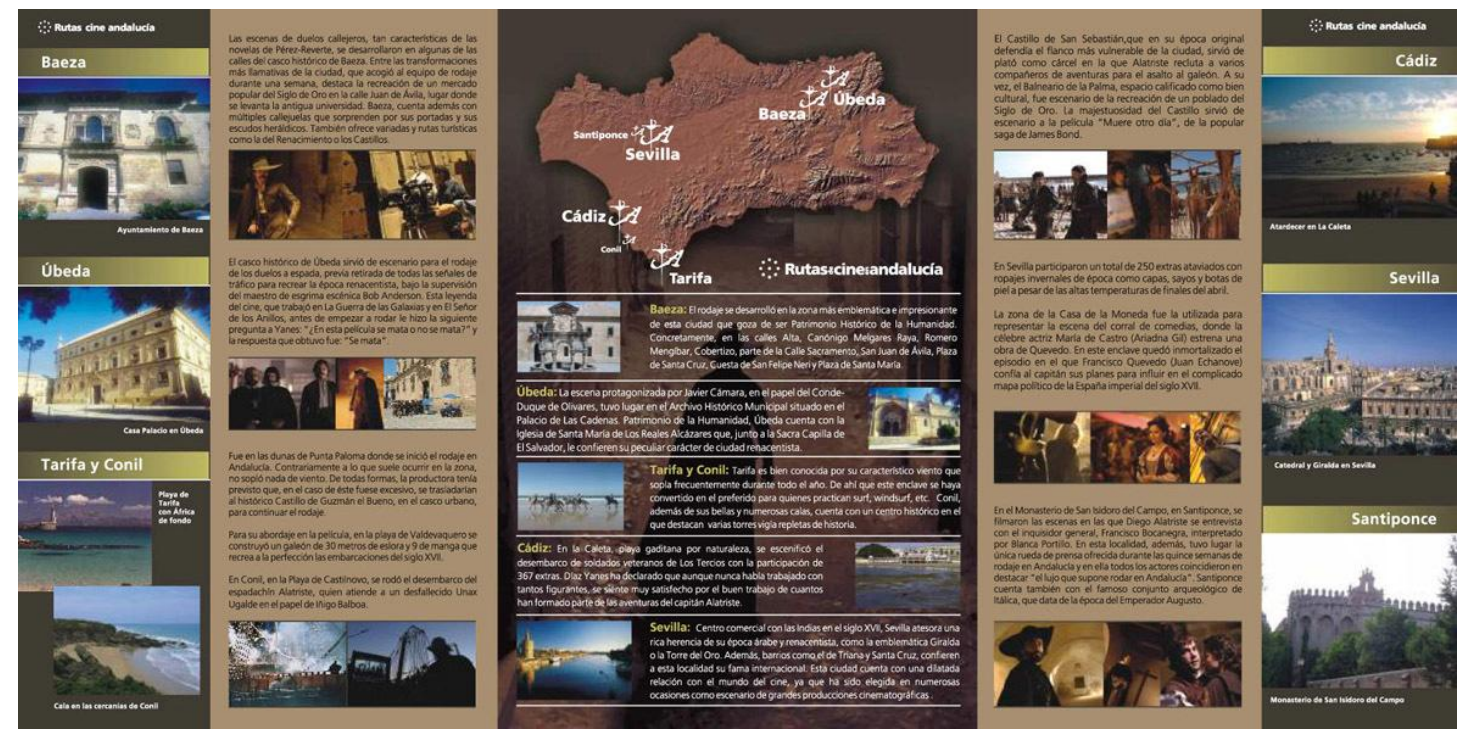

Fig. 2.2

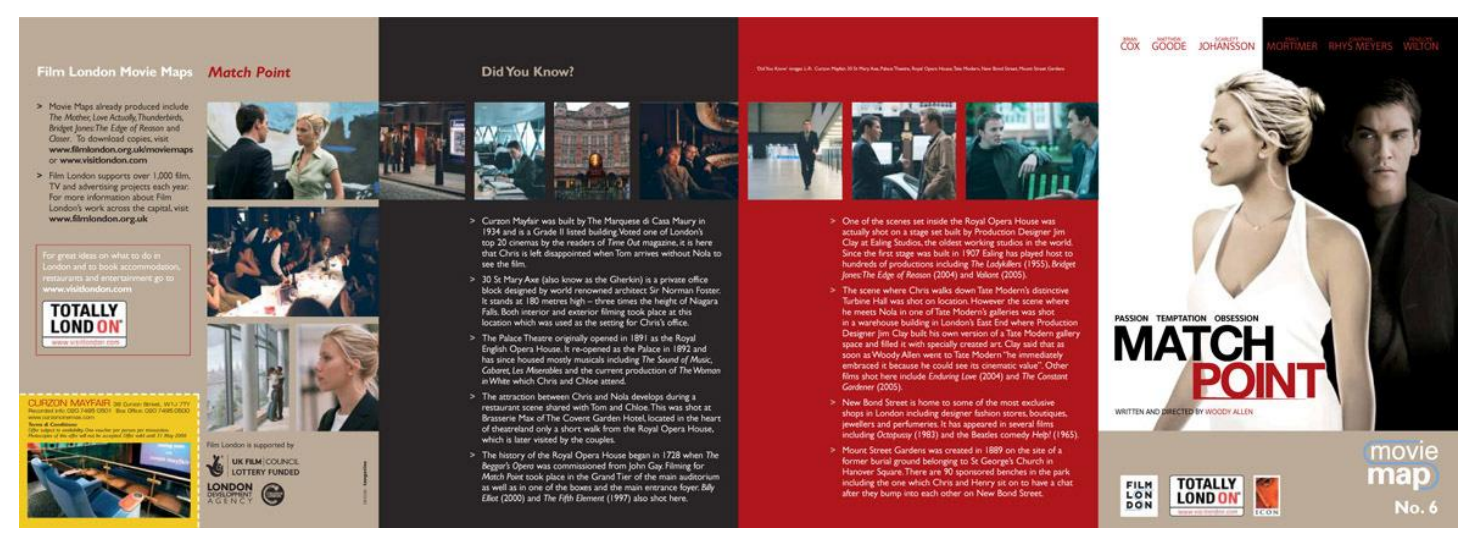

Fig. 3.1 
Marca turística y movie maps. Identidad, cine y publicidad como producto de consumo de Pedro A. Hellín Ortuño e Salvador Martínez Puche

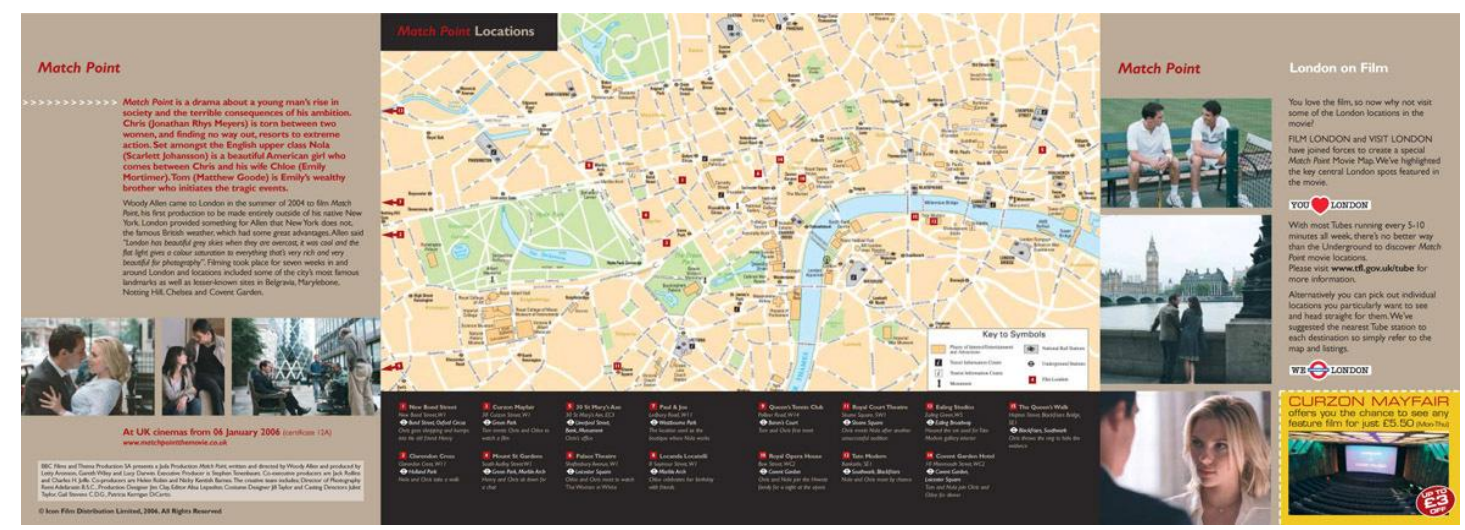

Fig. 3.2

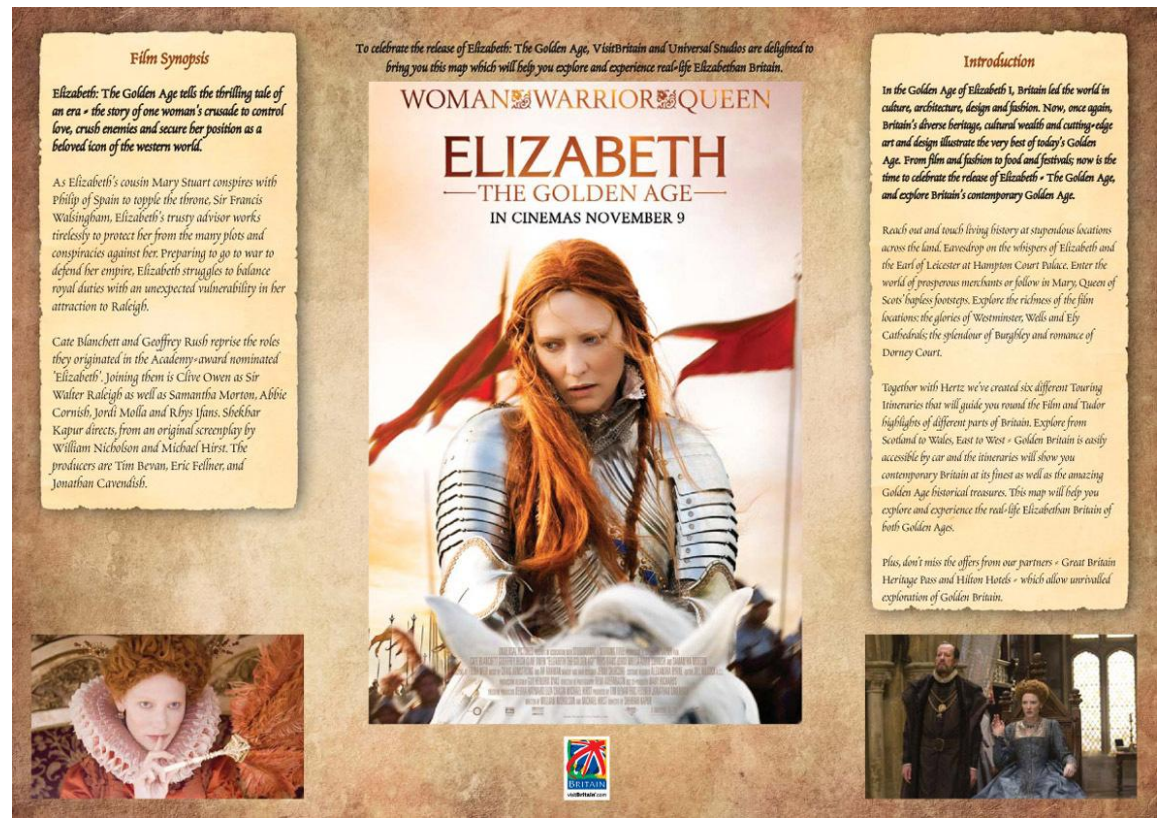

Fig. 4.1

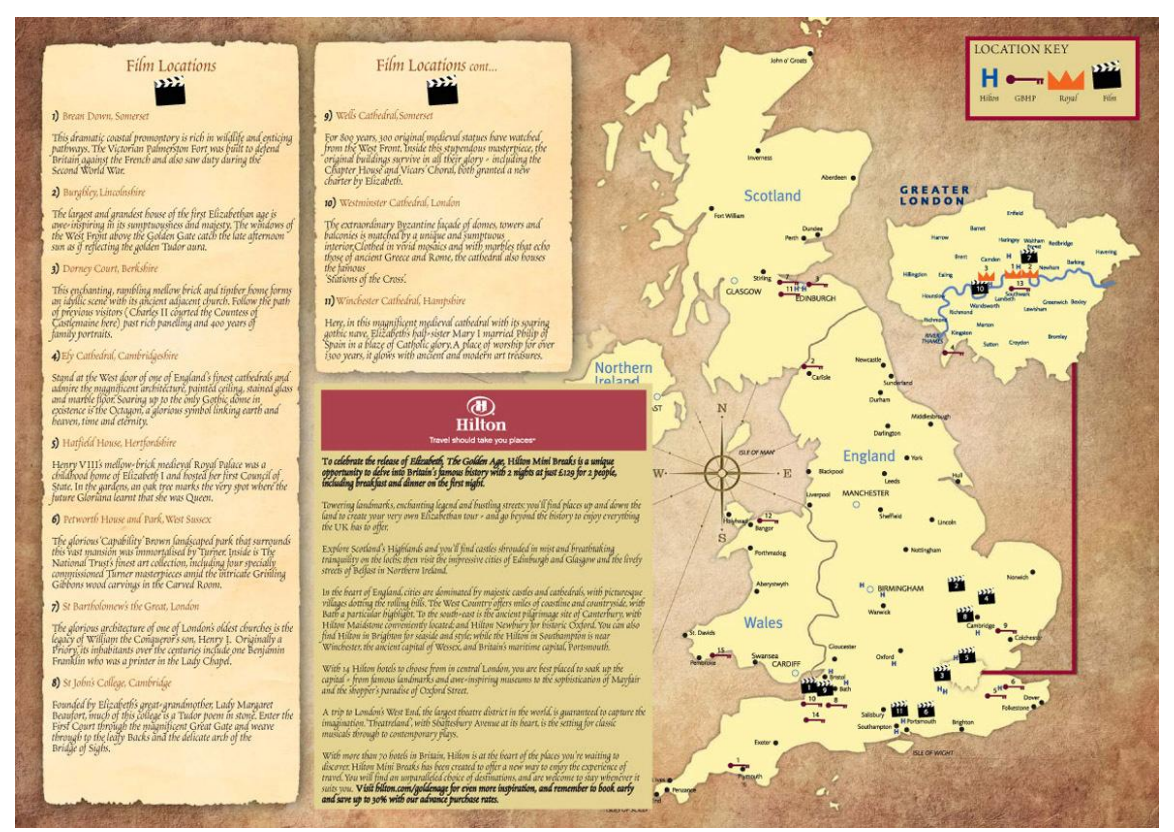

Fig. 4.2 


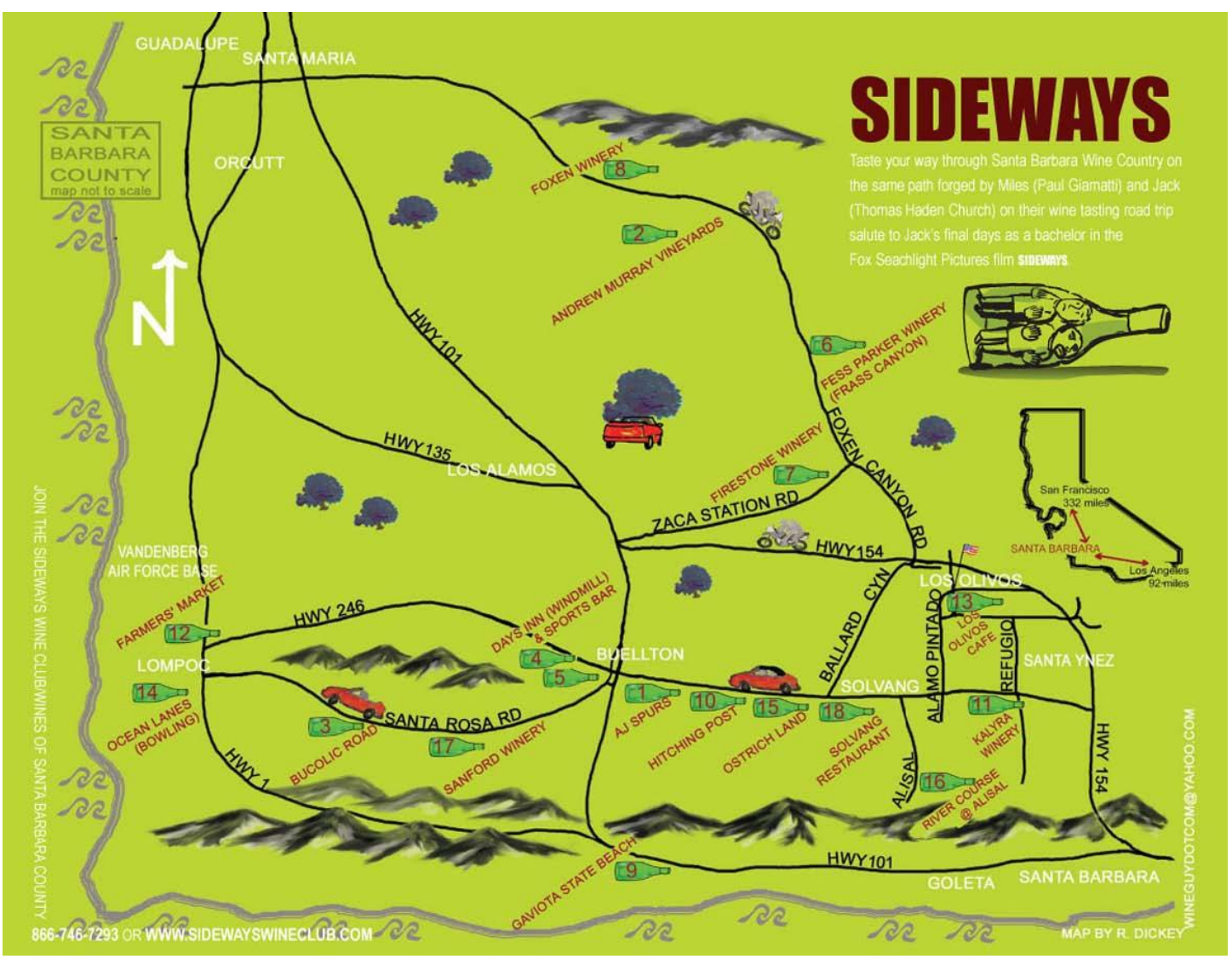

Fig. 5.1

\section{SIDEWAYS THE MAPP}

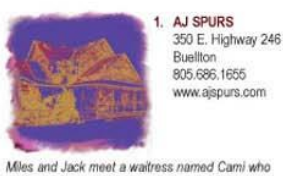

FESS PARKER WNERY 6200 Foxen Caryon R ${ }_{805.688 .1545}^{\log 0 \text { (inos }}$ 805.688. 1545

Frass Canyon's" large wine tasting event, Mies phones ins book will not be published. Afer

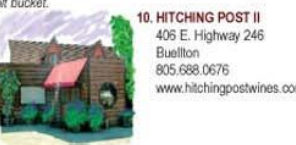

Miles and Jack share a bottie of hightiner at the bar. While

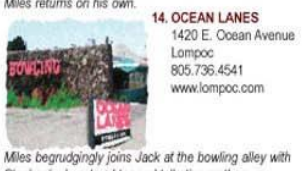

Miles begrudgingly joins Jack at the bowing alley with
Siphanie, her dacughter and takative mother.
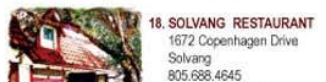

105.688.4545
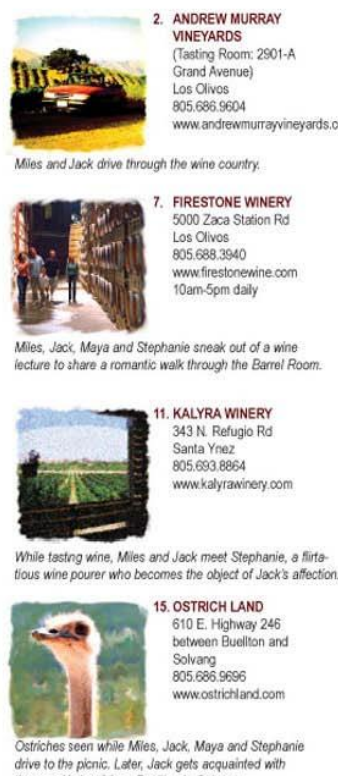

\section{SIDEWAYS TOUR TIPS} helmed by critcally aodamed director Alexander Payne his longtime scceenwiting partner, Jim Tayior based

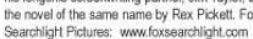
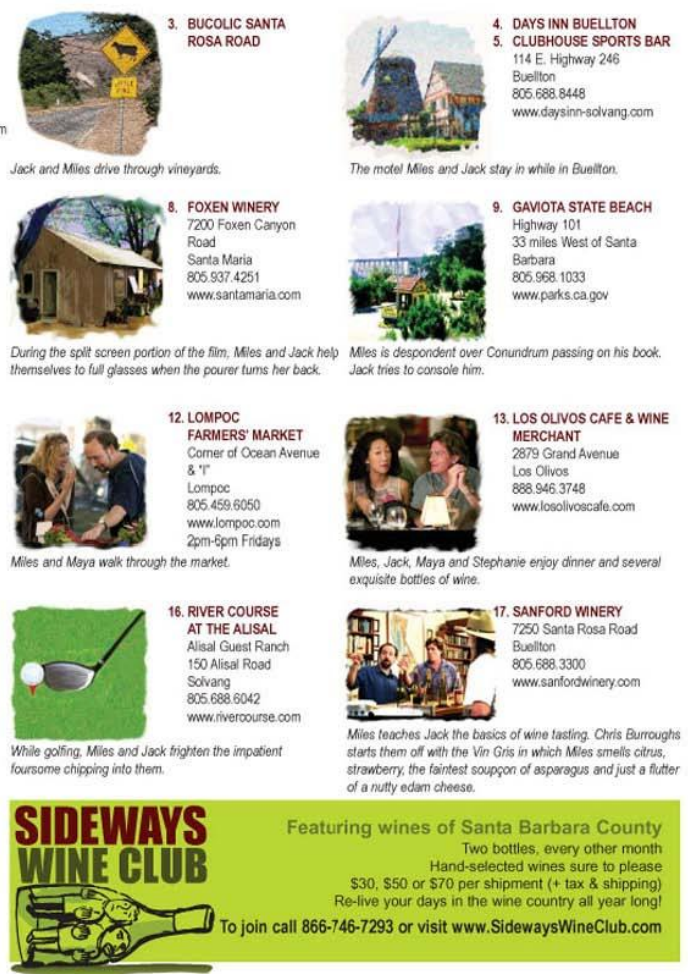

Fig. 5.2 
Marca turística y movie maps. Identidad, cine y publicidad como producto de consumo

A través de estas rutas y estos mapas el espacio geográfico adquiere un sentido inscripto y simbolizado, que transforma las coordenadas del lugar en la diégesis de un relato. El itinerario es "desviado" con una intención que persigue darle un "sentido" conforme a unas estrategias de marketing (Augé, 2004:89-90). Si como afirma Jameson (1991:115), tomando prestadas las nociones althusserianas, "la cartografía se presenta como la instancia clave en la mediación", los movie maps son la firme constatación de un "mapa cognitivo" que organiza el tránsito del viajero-turista según los datos de una vivencia cinematográfica anticipada.

\section{CONCLUSIONES}

El turista es consciente de su condición y de la condición de re-construcción de lo que le ofrecen durante su experiencia turística, es, ante todo, un buscador de iconos culturales. Los medios audiovisuales, como el cine, colonizan los imaginarios de los espectadores con sus atractivos entretenimientos, cada vez más hegemónicos, que estimulan e inducen a los fugaces colonizadores a aventurarse en los destinos turísticos, convertidos en no lugares, o sea, en palimpsestos cuyas huellas recuerdan la relación ficticia o imaginaria previa. La imagen antepone emociones a conceptos, de forma que no incita a reflexionar o mantener actitudes críticas, sino más bien a la asimilación inconsciente de una serie de imágenes que apuntan a los deseos, fobias, emociones y esperanzas de los individuos antes que a su capacidad analítica.

El fenómeno del movie tourism posee un marcado carácter de construcción cultural, que añade significados (de tipo emocional) al territorio, que es una construcción social y una compleja unidad de significado en la que interactúan el suelo (espacio), la memoria (tiempo) y un proyecto de futuro (representaciones). Para poder moverse en una dimensión surgida del deseo y la fantasía, es necesario "contar" con una cartografía adecuada. En este sentido, los relatos hermenéuticos de la experiencia cinematográfica actúan como eficaces mapas interpretativos y cognitivos y, por qué no, como útiles instrumentos para controlar al potencial viajero-consumidor y dirigir sus pasos por rutas temáticas inspiradas en los escenarios y las localizaciones de exitosas películas. La estrategia de construcción de la marca turística apoyada en el cine se basa, más que en ningún caso, en lo simbólico.

La forma más efectiva de crear una identidad de marca sólida y con proyección es conseguir que conecte con los intereses (racionales y/o emocionales) de los consumidores actuales y potenciales, asociándola a valores compartidos entre los públicos y la organización anunciante (en este caso el destino turístico), de forma que se establezcan 
Marca turística y movie maps. Identidad, cine y publicidad como producto de consumo

vínculos afectivos de reconocimiento y pertenencia y se desarrolle una corriente de simpatía que genere la satisfacción final. El movie map se revela de esta forma como una potente herramienta simbólica para la construcción de identidades de marca turística.

\section{REFERENCIAS BIBLIOGRÁFICAS}

AUGÉ, M. Los no lugares, espacios del anonimato. Una antropología de la sobremodernidad. Barcelona, Gedisa Editorial, 2004. BENET, V. J. Un siglo en sombras. Introducción a la historia y la estética del cine. Valencia, Contraluz, 1999.

BUSTAMANTE, E. "Regiones, televisión y desarrollo". In VACAS AGUILAR, F. (coord.). Televisión y Desarrollo. Las regiones en la era digital. Consejería de Educación, Ciencia y Tecnología. Cáceres, Junta de Extremadura, 2000, p. 15-22.

COHEN, E. "Principales tendencias en el turismo contemporáneo". Revista Política y Sociedad, Vol. 42, núm. 1, Madrid, 2005, pp. 11-24. DEL REY-REGUILLO, A. "Introducción” en Del Rey-Reguillo (ed), Cine, imaginario y turismo. Valencia, Tirant Lo Blanch, 2007, pp. 9-31. -“Celuloide hecho folleto turístico en el primer cine español”. En: Del Rey-Reguillo (ed.), Cine, imaginario y turismo, Valencia, Tirant Lo Blanch, 2007, pp. 147-175.

GÁMIR, A. \& VALDÉS, C. M. (2007): “Cine y geografía: espacio geográfico, paisaje y territorio en las producciones cinematográficas" In Boletín de la AGE (Asociación de Geógrafos Españoles), nº 45, Madrid, 2007, pp. 157-190.

GÓMEZ, F. J. Construcción de imaginarios: percepción, memoria e identificación en el discurso cinematográfico. Barcelona, BOCC, Biblioteca On-line de Ciencias de la Comunicación, 2002.

GONZÁLEZ REQUENA, J. El discurso televisivo: espectáculo de la posmodernidad. Madrid, Cátedra, 1999.

GUBERN, R. "La pantalla difusa" in Teleskop, revista digital de pensamiento y cultura. Sección Cine. Núm. 1, Vol. 1. Abril-junio, Barcelona, 2003, pp. 15-20.

HELLÍN ORTUÑO: "Publicidad verde. La ecología y el respeto al medio ambiente como estrategias persuasivas en la publicidad turística". En: CONTRERAS MEDINA, F. R. Cultura Verde. Ecología, Cultura y Comunicación. Consejería de Medio Ambiente, Junta de Andalucía. Sevilla, 2007. pp. 208-227

HERNÁNDEZ, J. "Turismo inducido. La configuración de la imagen turística de Sevilla a través del cine comercial". In: Actas I Congreso Internacional Patrimonio Desarrollo Rural y Turismo en el Siglo XXI. Osuna, 2004 
Marca turística y movie maps. Identidad, cine y publicidad como producto de consumo

JAMESON, F. El posmodernismo o la lógica cultural del capitalismo avanzado. Barcelona, Paidós Studio, 1991.

MACCANNELL, D. El turista. Una nueva teoría de la clase ociosa. Barcelona, Editorial Melusina, 2003.

REVISTA HOSTELTUR, Reportaje sobre turismo cinematográfico. Julio 2006. pp. 5-20.

RITZER, G.: La McDonalización de la sociedad. Un análisis de la racionalización en la vida cotidiana. Barcelona, Ariel, 1999

ROSADO, C. \& QUEROL, P. Cine y turismo. Una nueva estrategia de promoción. Madrid, Ed. Ocho y Medio, Junta de Andalucía y Andalucía Film Commission, 2006.

SANDOVAL, M. T. (1998): "Promoción turística a través del sector audiovisual. El caso de Canarias”. In Revista Latina de Comunicación. La Laguna (Tenerife), nº 9, 1998.

SAN NICOLÁS ROMERA, C. (2008): "La industria del turismo cultural y mecanismos publicitarios de codificación de experiencias en un contexto global". En: MARTÍNEZ PUCHE, A., PRIETO CERDÁN, A Y RODRÍGUEZ GUTIÉRREZ, F. (coords.) Los sistemas locales de empresas y el desarrollo territorial: Evolución y perspectivas actuales en un contexto globalizado. San Vicente del Raspeig (Alicante), Editorial Club Universitario, 2008.

URRY, J. The Tourist Gaze: Leisure and Travel in Contemporary Societies, Sage, Newbury Park, CA, 1990. VIRILIO, P. La máquina de la visión. Madrid, Cátedra, Colección Signo e Imagen, 1989.

Artigo recebido em 21/6/2009.

Aprovado em 23/8/2009. 